\title{
ФОРМИРОВАНИЕ ГОТОВНОСТИ СТУДЕНТОВ К КОРРЕКЦИОННОЙ РАБОТЕ ПО РАЗВИТИЮ ЭМОЦИОНАЛЬНО- ВОЛЕВОЙ СФЕРЫ У УМСТВЕННО ОТСТАЛЫХ ДОШКОЛЬНИКОВ С РАССТРОЙСТВАМИ АУТИСТИЧЕСКОГО СПЕКТРА ${ }^{1}$
}

\section{FORMATION OF STUDENTS READINESS \\ FOR CORRECTIONAL WORK ON THE DEVELOPMENT OF THE EMOTIONAL AND VOLITIONAL SPHERE IN MENTALLY RETARDED PRESCHOOLERS WITH AUTISM SPECTRUM DISORDERS}

\author{
E. Zolotkova \\ M. Lavrentieva \\ O. Grishina
}

Summary: The article deals with the problem of formation of students 'readiness for correctional work on the development of the emotionalvolitional sphere in mentally retarded preschoolers with autism spectrum disorders; highlights the results of research on the level of formation of students' readiness for this type of activity; reveals approaches to its formation, through professional and pedagogical tasks in the framework of the research laboratory.

Keywords: readiness, correctional work, emotional-volitional sphere, mentally retarded preschoolers with autism spectrum disorders.
Золоткова Евгения Вячеславовна

К.n.н., дочент, ФГБОУ ВО «Мордовский государственный педагогический институт им. М.Е. Евсевьева» (г. Саранск) zzolotkova@yandex.ru

Лаврентьева Марина Анатольевна К.п.н., дочент, ФГБОУ ВО «Мордовский государственный педагогический институт им. М.Е. Евсевьева» (г. Саранск)

lavrentyeva1866@yandex.ru

Грииина Ольга Сергеевна старший преподаватель, ФГБОУВО «Мордовский государственный педагогический институт им. М.Е. Евсевьева» (2. Саранск) grishina0609@yandex.ru

Аннотация: В статье рассматривается проблема формирования готовности студентов к коррекционной работе по развитию эмоционально-волевой сферы у умственно отсталых дошкольников с расстройствами аутистического спектра (РАС); освещаются результаты исследования уровня сформированности готовности студентов к данному виду деятельности; раскрываются подходы к ее формированию, посредствами профессионально-педагогических задач в рамках деятельности научно-исследовательской лаборатории.

Ключевые слова: готовность, коррекционная работа, эмоционально-волевая сфера, умственно отсталые дошкольники с расстройствами аутистического спектра.

ориентироваться в простейших бытовых ситуациях, аутоагрессией, стереотипиями и т.д. Комплекс специфических проявлений нарушений эмоционально-волевой сферы у детей с данным сочетанным дефектом предопределяет весь процесс коррекционной работы. Он становиться возможен только при создании специальных условий для реализации которых у педагога-дефектолога должен быть сформирован набор определенных трудовых функций и действий. В связи с этим, в рамках профессионального обучения будущих педагогов-дефектологов необходимо целенаправленно формировать готовность к работе с такими детьми.

Анализ исследований показал, что структура инклюзивной готовности педагога представлена следующими нотипными моделями поведения, неумением адекватно обусловлено тем, что данная категория детей обладает специфическими типологическими характеристиками, связанными с ограничением вербальной и невербальной коммуникации, экстремальным одиночеством, од-

Исследование выполнено в рамках гранта Российского фонда фундаментальных исследований по теме «Проектирование коррекционно-развивающей работы по развитию эмоционально-волевой сферы у умственно отсталых дошкольников с расстройствами аутистического спектра» (№ 20-013-00367). 
компонентами: мотивационно-ценностным, когнитивным, операционально-деятельностным и рефлексивнооценочным. Целостный характер готовности студента к профессиональной деятельности дефектолога способствует взаимосвязанному функционированию всех ее компонентов в процессе разрешения возникающих задач, ситуаций, проблем. Как правило, сложность решаемой задачи определяет полноту участия определенного компонента в ее решении.

Формирование готовности педагога-дефектолога к коррекционной работе по развитию эмоционально-волевой сферы у умственно отсталых дошкольников с РАС будет результативным благодаря созданию специальных образовательных условий, приближающих студента к ситуации реального взаимодействия с умственно отсталым ребенком с РАС.

В данной статье рассматривается проблема целенаправленной практико-ориентированной подготовки студентов к коррекционной работе по развитию эмоционально-волевой сферы у умственно отсталых дошкольников с РАС через формирование готовности средствами решения профессионально-педагогических задач.

\section{Обзор литературы}

Социальный запрос требует от выпускников, обучающихся на направлении подготовки Специальное (дефектологическое) образование, владение специальными компетенциями, обеспечивающих их готовность к коррекционной работе по развитию эмоционально-волевой сферы у умственно отсталых дошкольников с РАС.

В многочисленных исследованиях под готовностью понимается свойство личности, которое позволяет человеку осознавать себя способным к осуществлению определенной профессиональной деятельности [2; 4; 7].

В структуре готовности студента к осуществлению коррекционной работы с умственно отсталыми дошкольниками с РАС, также, как и в готовности педагога исследователи выделяют несколько взаимосвязанных компонентов, а именно мотивационно-ценностный, когнитивный, операционально-деятельностный и рефлексивно-оценочный. Все перечисленные компоненты содержат совокупность профессиональных и личностных компетенций [3].

В работах С. Никольской, Е.Р. Баенской, М.М. Либлинг подчеркивается, что эмоционально-волевая сфера умственно отсталых дошкольников с РАС характеризуется низкой эмоциональностью, отсутствием использования выразительных средств (мимика, пантомимика, интонация), ограниченным спектром эмоций, недостаточным произвольным регулированием их поведения, нежела- нием прилагать усилия для достижения результата в собственной деятельности [5, с. 18].

В связи с этим, можно утверждать, что содержание готовности педагога-дефектолога определяется спецификой организации образовательного пространства, необходимого для умственно отсталых дошкольников с РАС; основными аспектами профессиональной деятельности дефектолога; комплексом профессиональных и личностных компетенций, определяющих направленность коррекционной работы с такими детьми.

В работах М.А. Лаврентьевой, О.С. Гришиной анализируется готовность педагогов к супервизии. Обобщение данных исследований дает возможность утверждать, что мотивационно-ценностный критерий готовности позволяет оценить понимание студентом сущности коррекционной работы по развитию эмоционально-волевой сферы у умственно отсталых дошкольников с РАС; мотивы к осуществлению необходимых действий в работе с такими детьми; потребность обобщения накопленных знаний, умений, навыков. Другой критерий готовности, операционально-деятельностный, указывает на умения находить ресурсы необходимые для организации помощи детям; строить процесс дефектологической практики в указанном направлении; применять технологии коррекционной работы по развитию эмоционально-волевой сферы указанной категории детей; строить собственную деятельность на основе принципов междисциплинарного взаимодействия специалистов. Умения проводить анализ трудностей, возникающих в процессе проведения коррекционной работы по развитию эмоционально-волевой сферы; учет индивидуальных проявлений каждого ребенка; рефлексия эффективности собственной деятельности; стремление к профессиональному саморазвитию заложены в рефлексивно-оценочном критерии готовности [2, с. 57].

Одним из способов погружения в практико-ориентированную деятельности студентов является использование активных методов которые побуждают обучаемых к активной познавательной деятельности, преобразующуюся в практическую, по мнению различных исследователей, к ним относятся моделирование реальных ситуаций, деловые игры, кейс-метод или метод анализа конкретной ситуации, решение профессионально-педагогических задач и др. $[1 ; 6]$. Потенциальные возможности формирования готовности студентов к будущей профессии заложены в практико-ориентированной деятельности студентов в рамках научно-исследовательских лабораторий. Формат научно-исследовательской лаборатории позволяет студентам моделировать реальные ситуации взаимодействия субъектов образовательной деятельности.

Таким образом, готовность педагога-дефектолога к 
коррекционной работе по развитию эмоционально-волевой сферы у умственно отсталых дошкольников с РАС характеризуется как открытая, сложная, развивающаяся и самоорганизующаяся система.

\section{Материалы и методы}

В исследовании использованы теоретические (анализ, систематизация и обобщение данных, представленных в психолого-педагогической, научно-методической и учебной литературе) и эмпирические (анкетирование студентов-бакалавров, проектирование практико-ориентированной деятельности студентов по формированию готовности) методы.

В исследовании приняли участие 20 студентов 4 курса направления подготовки Специальное (дефектологическое) образование.

\section{Результаты исследования}

Исследование готовности студентов к коррекционной работе по развитию эмоционально-волевой сферы у умственно отсталых дошкольников с РАС проводилось с помощью анкетирования, которое позволило выявить сформированность мотивационно-ценностного, когнитивного, операционально-деятельностного и рефлексивно-оценочного компонентов готовности.

Результаты исследования готовности студентов к коррекционной работе по развитию эмоционально-волевой сферы у умственно отсталых дошкольников с РАС показали, что у 71,5 \% студентов отмечается элементарный уровень готовности, который не дает возможности осуществлять этот вид коррекционного воздействия и выполнять элементарные задачи сопровождения данной категории детей. На репродуктивном уровне оказалось 28,5 \% респондентов, они обладали базовыми предпосылками готовности необходимыми для включения в коррекционную работу с такими детьми, однако их явно недостаточно для достижения положительного эффекта в коррекционной работе с такими детьми.

Готовность к профессиональной деятельности педагога-дефектолога креативного уровня не была выявлена у участников эксперимента. Это обусловлено недостаточно сформированными у студентов компонентами готовности и компетенциями, обеспечивающими полноту выбора технологий для осуществления эффективной коррекционной работы с умственно отсталыми дошкольниками с РАС.

Формирование готовности студентов к коррекционной работе по развитию эмоционально-волевой сферы у умственно отсталых дошкольников с РАС проходило на практических занятиях в рамках деятельности На- учно-исследовательской лаборатории (НИЛ) «Интегрированное обучение и воспитание детей в системе образования» на базе кафедры специальной педагогики и медицинских основ дефектологии.

Практико-ориентированная работа студентов в рамках НИЛ «Интегрированное обучение и воспитание детей в системе образования», рассматривается нами, как форма образовательного процесса, которая позволяет конструировать и реализовывать технологии коррекционного процесса, направленного на преодоление недостатков эмоционально-волевой сферы у умственно отсталых дошкольников с РАС.

В соответствии с требованиями ФГОС 3++ был определен перечень обязательных профессиональных компетенций, относящихся к типу задач профессиональной деятельности «сопровождение», которые необходимо для осуществления коррекционной работы по развитию эмоционально-волевой сферы у умственно отсталых дошкольников с РАС.

ПКО-6. Способен проводить психолого-педагогическое изучение особенностей психофизического развития, образовательных возможностей, потребностей и достижений лиц с ОВ3.

ПКО-7. Способен осуществлять консультирование и психолого-педагогическое сопровождение лиц с ОВ3, членов их семей и представителей заинтересованного окружения по вопросам образования, развития, семейного воспитания и социальной адаптации.

В качестве примера представляем несколько типов профессионально-педагогических задач, призванных формировать у студентов практико-ориентированные навыки работы с данной категорией детей в рамках деятельности НИЛ «Интегрированное обучение и воспитание детей в системе образования».

1. Смоделируйте этапы коррекционно-развивающего занятия для умственно отсталых дошкольников, имеющих РАС на котором решаются следующие задачи.

Задачи:

Коррекционно-образовательные:

1) закреплять правила доброжелательного поведения, развивать навыки взаимодействия со сверстниками;

2) совершенствовать умения использования красок, карандашей, фломастеров;

3) формировать мотивацию деятельности;

4) продолжать учить детей давать нравственную оценку того или иного героя в соответствии с нормами морали. 
Коррекционно-развивающие:

1) развивать гуманное отношение к окружающему миру, эмоционально-волевую сферу и творческие способности через элементы сказкотерапии;

2) развивать произвольное внимание, мелкую моторику.

Коррекционно-воспитательные:

1) воспитывать усидчивость, коммуникабельность;

2) воспитывать добрые чувства, уверенность в себе.

2. Подберите речевой материал для обучения аналитико-синтетическому чтению детей с РАС в соответствии с видами работы, указанными ниже:

1) лото с карточками, на которых изображены начальные буквы названий картинок;

2) упражнения, помогающие дольше фиксировать взор ребенка на букве, и расширяющие спектр его произвольных действий;

3) упражнения по подбору картинок на определенные звуки;

4) альбом-азбука для засовывания картинок на определенный звук.

Подготовьте стимульный материал к разработанному комплексу упражнений для его презентации перед студентами группы.

3. Составьте план беседы с родителями умственно отсталого ребенка с расстройством аутистического спектра на первичном приеме у педагога.

4. Спроектируйте направления психолого-педагогической работы с родителями, воспитывающими умственно отсталых детей с эмоционально-волевыми нарушениями.

5. Подготовьте план-конспект для подгруппового занятия с умственно отсталыми дошкольниками, имеющими РАС, на котором решаются следующие цели и задачи.

Цель: расширение представлений детей об эмоциях.

Задачи:

Коррекционно-образовательная:

1) совершенствовать умения использования речи для объяснения своего эмоционального состояния;

2) приучать детей активно выполнять движения по показу педагога.

Коррекционно-развивающая:

1) развивать крупную моторику;

2) развивать умение различными эмоциональными средствами передавать заданное эмоциональное состояние;

3) развивать умение заботиться о других.

Коррекционно-воспитательная:

1) воспитывать усидчивость, коммуникабельность;

2) воспитывать потребности оказать помощь другим.

6. Разработайте проект программы логопедической помощи для дошкольника с РАС с учетом следующих компонентов: диагностический, коррекционный, консультативный (для родителей). Презентуйте содержание разработанной программы логопедической помощи с использованием PowerPoint, обсудите эффективность еe реализации со студентами группы.

По итогам проведения исследования был проведен контрольный эксперимент для определения уровня сформированности готовности студентов к проведению коррекционной работы с умственно отсталыми дошкольниками с РАС, который продемонстрировал выраженную позитивную динамику.

\section{Обсужмение и закАючения.}

В многочисленных исследованиях подчеркивается наметившаяся в последнее время тенденция увеличения числа детей со сложной структурой дефекта. Коррекционная работа с такими детьми предъявляет новые требования к профессиональной подготовке будущих специалистов, обучающихся по направлению подготовки Специальное (дефектологическое) образование. Проведение коррекционной работы по развитию эмоционально-волевой сферы умственно отсталых дошкольников с РАС требует не только знание специфических технологий, но и умение их применять в соответствии с сугубо индивидуальными возможности аутичного ребенка. Исследование готовности студентов к осуществлению данного вида деятельности показала, что у подавляющего большинства она соответствует элементарному, базовому уровню.

Формирование у студентов готовности к проведению коррекционной работы по развитию эмоционально-волевой сферы у умственно отсталых дошкольников с РАС наиболее эффективна в рамках деятельности НИЛ «Интегрированное обучение и воспитание детей в системе образования». Основной формой формирования готовности является практико-ориентированная деятельность студентов в процессе решения профессиональнопедагогических задач.

Обобщение результатов контрольного эксперимента указывает на значительную динамику в направлении развития готовности студентов к коррекционной работе по развитию эмоционально-волевой сферы у умственно отсталых дошкольников с РАС. 


\section{ЛИТЕРАТУРА}

1. Белова, Н.А. Моделирование и решение профессиональных задач в процессе подготовки мобильного учителя русского языка / Н.А. Белова, Л.П. Водясова, Е.А. Кашкарева, Д.В. Макарова // Гуманитарные науки и образование. - 2019. - Том 10. - № 1. - С. 12-19.

2. Лаврентьева, М.А. Супервизия как основа практико-ориентированной подготовки будущих педагогов специального (дефектологического) образования / М.А. Лаврентьева, О.С. Гришина // Теория и практика подготовки дефектологов в условиях модернизации образования: монография / под ред. Н.В. Рябовой; Мордов. гос. пед. ин-т. - Саранск, 2017. - С. 56-79.

3. Лазарев, В.С. Деятельностный подход к новому пониманию целей высшего образования [Электронный ресурс] / В.С. Лазарев // Инноватика в образовании. Электронный научно-практический журнал. - 2014, февраль. - URL: http://invobr.ru.

4. Марголис, А.А. Требования к модернизации основных профессиональных образовательных программ (ОПоП) подготовки педагогических кадров в соответствии с профессиональным стандартом педагога: предложения к реализации деятельностного подхода в подготовке педагогических кадров [Электронный ресурс] / А.А. Марголис // Психологическая наука и образование psyedu.ru. 2014. - Том 6. - № 2. - C. 1-18. - URL: http://psyedu.ru/ journal/2014/2/Margolis.phtml (дата обращения: 08.10.2019).

5. Никольская, О.С. Аутичный ребенок. Пути помощи / О.С. Никольская, Е.Р. Баенская, М.М. Либлинг. - М. : Теревинф, 2015. - 288 с.

6. Неясова, И.А. Профессиональная проба как средство практико-ориентированной подготовки будущего педагога / И.А. Неясова, С.Н., Горшенина, Л.А. Серикова // Гуманитарные науки и образования. 2018. 9(4). С. 105-110.

7. Шукшина, Т.И. Развитие системы научно-исследовательской и проектной деятельности студентов в условиях многоуровневой системы высшего педагогического образования / Т.И. Шукшина, П.В. Замкин, И.И. Парватова // Гуманитарные науки и образование. - 2013. - № 4. - С. 47-54.

( ) Золоткова Евгения Вячеславовна (zzolotkova@yandex.ru), Лаврентьева Марина Анатольевна (lavrentyeva1866@yandex.ru), Гришина Ольга Сергеевна (grishina0609@уandex.ru).

Журнал «Современная наука: актуальные проблемы теории и практики»

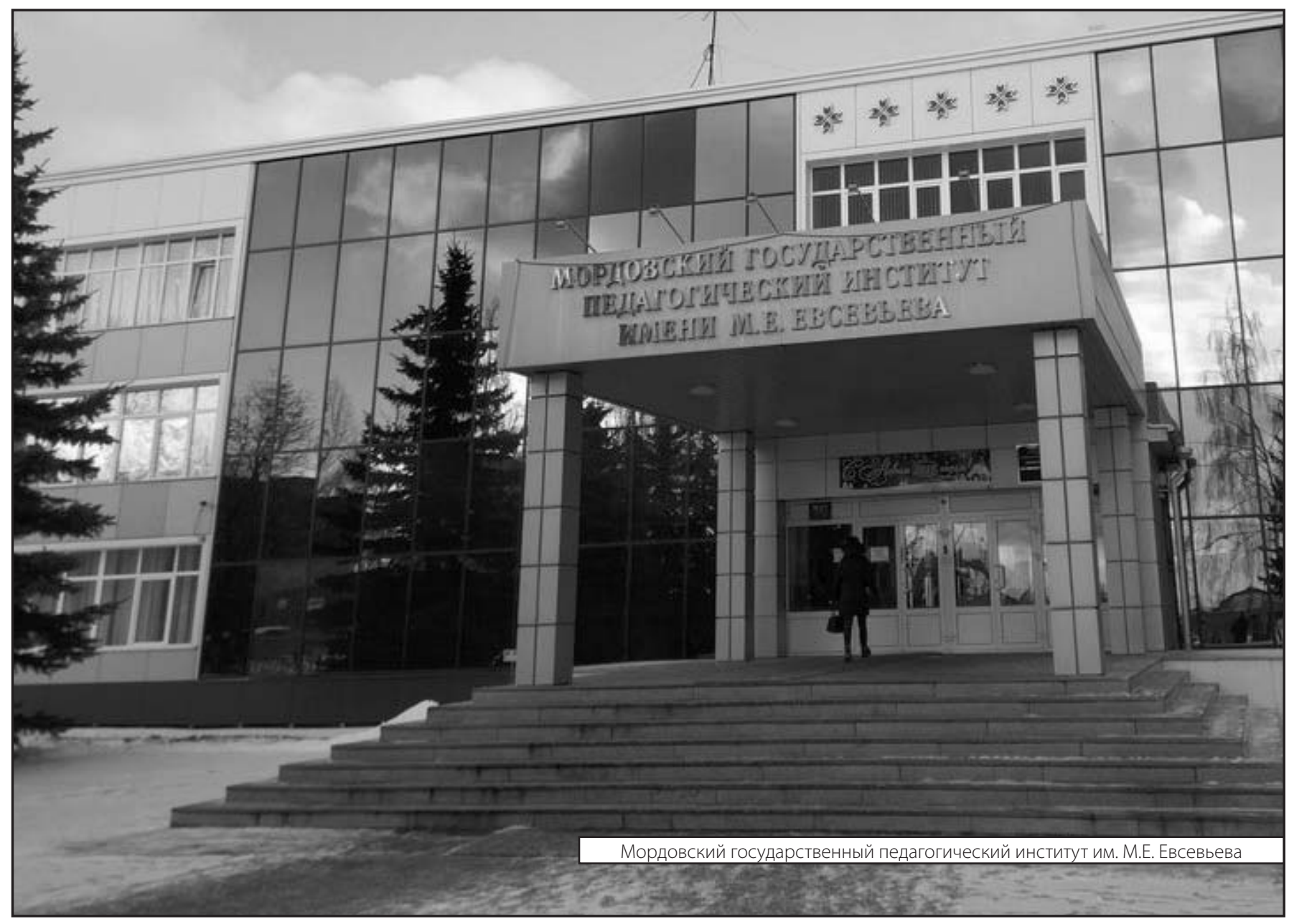

